\title{
THE IMPACT OF PHYSICAL ACTIVITY AND DIETARY MEASURES ON THE BIOCHEMICAL AND ANTHROPOMETRIC PARAMETERS IN OBESE CHILDREN. IS THERE ANY GENETIC PREDISPOSITION?
}

\author{
Lukáš Zlatohlávek ${ }^{1}$, Jaroslav Alois Hubáček ${ }^{2}$, Michal Vrablík', Hana Pejšová ${ }^{1}$, Věra Lánská ${ }^{2}$, Richard Češka $^{1}$ \\ ${ }^{13}$ rd Department of Internal Medicine, General University Hospital and 1st Faculty of Medicine, Charles University, Prague, Czech Republic \\ ${ }^{2}$ Centre for Experimental Medicine, Institute for Clinical and Experimental Medicine, Prague, Czech Republic
}

\section{SUMMARY}

Aim: The aim of the study was to monitor the importance of laboratory, anthropometric and genetic determination of the presence of risk factors for atherosclerosis, obesity, dyslipidemia and components of the metabolic syndrome in obese children and the response to dietary and regimen interventions in obese children.

Methods: As a part of the study, 353 paediatric patients (46\% boys, 54\% girls) with obesity and dyslipidemia, aged 8-16 years, participated in a one-month lifestyle intervention programme. The programme involved a reduction of energy intake and supervised exercise programme consisting of 5 exercise units per day, each 50 minutes long. Standard biochemical methods were applied, including Lp-PLA2, as were anthropometric measurements and genetic analyses.

Results: During the reduction programme for the children there was a statistically significant decrease in all anthropometric indicators of bodyweight $(p<0.001)$ as well as in lipid parameters and LpLPA2. Carriers of the FTO GG genotype and/or MC4R CC genotype lost significantly more body weight in comparison to non-carriers.

Conclusion: Child obesity is an important social issue. After regimen interventions, there is weight loss as well as an improvement in biochemical parameters. There are individuals with a genetic predisposition for obesity, as well as individuals with a better response to regimen interventions which could, among other things, be determined by the FTO and MC4R genotypes.

Key words: child obesity, risk factors, regimen intervention, genetic predisposition

Address for correspondence: L. Zlatohlávek, III. Internal Clinic GUH and 1. MF UK, U Nemocnice 1, 12808 Prague, Czech Republic. E-mail: lukas.zlatohlavek@lf1.cuni.cz

\section{INTRODUCTION}

At present, atherosclerosis, or rather cardiovascular disease (CVD), is one of the most common causes of mortality and morbidity in developed countries. One of the most important ways to reduce the prevalence of cardiovascular disease is the reduction of the risk factors linked to atherosclerosis. The risk factors for atherosclerosis are divided into non-influenceable (age, sex, family history of serious cardiovascular disease) and influenceable (including dyslipidemia, diabetes mellitus, arterial hypertension, smoking, obesity, and low physical activity). In addition, the accumulation of risk factors in one individual does not culminate in the risk of CVD, it multiplies it. For example, the presence of dyslipidemia and arterial hypertension increases the risk of CVD nine times; the additional presence of smoking increases the risk of CVD sixteen times (1).

Although these risk factors appear to relate to adult age, their prevalence is shifting to ever-younger age groups, even to childhood (2). The presence of certain risk factors in childhood is alarming. For example, in the Czech Republic, $6 \%$ of children suffer from obesity, and $9 \%$ of children are overweight, $23 \%$ of children have dyslipidemia and $1.8 \%$ suffer from arterial hypertension (3). According to WHO, in the age group of 15-18 years, $16 \%$ of boys and $11 \%$ of girls are smokers. The incidence of diabetes mellitus is distorted, in particular due to the prevalence of type 1 diabetics; however, cases of type 2 diabetes mellitus occur more frequently in childhood, which used to be the prerogative of adults (4).

The causes of the increased prevalence of risk factors are in particular lifestyle changes, reduced physical activity and changes in the eating habits of children. This increasingly allows phenotypic manifestations of gene polymorphisms involved in the presence of obesity, metabolic syndrome and dyslipidemia to be unmasked (5).

The prevention and treatment of the above described risk factors for atherosclerosis is both non-pharmacological and pharmacological. Non-pharmacological intervention is primarily recommended for children. This includes the consistent and regular dietary education of the paediatric patients as well as their parents or family members. Furthermore, regular physical activity 
is essential. At the same time it is necessary to motivate parents and children to implement these measures themselves and to check their compliance through regular check-ups (6).

In order to consistently prevent subsequent complications resulting from the accumulation of risk factors that may manifest themselves in early adulthood, it is extremely important to select children who already have the risk factors present.

The Children's Sanatorium of Dr. L. Filip in Podebrady mainly organizes programmes for children with diseases of the musculoskeletal system, cardiovascular apparatus, dyslipidemia, arterial hypertension, but also treatments for childhood obesity. This represents a selected group of children with a high accumulation of risk factors linked to atherosclerosis.

A series of clinical studies with large numbers of patients have not only shown that dietary and regimen measures lead to weight loss and a reduction in waist circumference, but that there is also an improvement in laboratory indicators and reduction in cardiovascular risk (7).

The effect of diet and exercise interventions on the weight reduction and improvements in laboratory monitored parameters in children varies. The results are likely to be affected by a combination of differences in their internal environment (metabolism, genetic predisposition) and the influence of their external environment (8).

In literature, discussions focus on a number of specific genetic variants which have the potential to influence their reactions to dietary and regimen measures. The most analysed are polymorphisms of the FTO (fat mass and obesity related gene, OMIM acc. No 610966) (9) and MC4R (melanocortin 4 receptor, OMIN acc. No 155541) genes (10-12).

Lp-PLA2, phospholipase A2 associated with lipoproteins, is an enzyme produced by cells of the monocyte-macrophage system, in particular by inflammatory cells of atherosclerotic plaque. The largest producers are the macrophages and foam cells in the subendothelial space. Previous studies refer to a higher concentration of Lp-PLA2 in vulnerable atheromatous plaques. In circulation, Lp-PLA2 is largely bound to the carboxyl terminus of the apoB-100 LDL particles (up to $80 \%$ ); the remaining part is bound to HDL, VLDL and Lp(a). It appears that there is a greater association with the small dense LDL particles. An increase in the concentration of, or activities relating to, Lp-PLA2 are associated with an increase in cardiovascular risk $(13,14)$.

Lp-PLA2 activity is influenced by a number of factors: hypolipidemics, antihypertensives and a number of other agents. It is assumed that increased physical and dietary interventions also affect the lipoprotein lipase activity. A group of local children undergoing weight loss programmes is a suitable model for studying the effects of regimen and dietary measures on Lp-PLA2 levels.

\section{MATERIALS AND METHODS}

As a part of the study 353 paediatric patients were examined. The patients ( $46 \%$ boys, $54 \%$ girls) suffering from obesity and dyslipidemia were aged $8-16$ years and participated in a onemonth programme at the Children's Sanatorium of Dr. L. Filip in Podebrady. The examinations were carried out at the beginning and at the end of their hospitalization (14).
The children with obesity participating in the study were prescribed a weight reduction diet according to their age. Children under 10 years of age received 5,000 kcal/day, children over 10 years of age $7,000 \mathrm{kcal} /$ day. Children with hypercholesterolemia received a low cholesterol diet. The exercise programme consisted of aerobic and resistance training ( 5 units a day, each 50 minutes long) complemented with ball games, swimming, dancing, and fast walking.

Upon arrival, the children and their parents received information about the project. If the parents, the legal guardians of the child, consented to their child's participation in the project, they signed an informed consent form.

The following examinations were carried out: measurement of anthropometric parameters (height, weight, calculation of Body Mass Index, waist, abdomen and hip circumferences as well as skinfold over the left triceps, below the right scapula and abdominal skinfold).

All participants underwent a thorough physical examination prior to entering and leaving the programme. Body weight was measured with a calibrated electronic weight scale. Height was measured to the nearest $0.5 \mathrm{~cm}$. Waist and hip circumferences were also measured with an accuracy of $0.5 \mathrm{~cm}$. BMI $\left(\mathrm{kg} \mathrm{per} \mathrm{m}^{2}\right)$ was calculated on the basis of obtained measurements. Diastolic and systolic blood pressures were measured after 10 minutes in a sitting position using a mercury manometer. The skinfold thickness was measured with a BEST II-501 calliper. Total body fat was determined by impedance analysis using a Bodystat analyser (1500 MDD, Bodystat, Isle of Man, UK).

The blood test measured total cholesterol, LDL-, HDL- cholesterol, triglycerides, apolipoprotein A, apolipoprotein B, lipoprotein (a), blood glucose level, C-peptide and insulin level. Basic biochemical tests (sodium, potassium, chloride, urea, creatinine, liver function tests, TSH) were also carried out.

Total cholesterol, HDL cholesterol, triglycerides, apolipoprotein A, apolipoprotein B, lipoprotein (a), gamma-glutaryl transferase, and basic biochemistry parameters were measured in the central laboratory of the General University Hospital (Institute of Clinical Biochemistry and Laboratory Diagnostics, 1st Faculty of Medicine, Charles University and General University Hospital). The results for LDL cholesterol were calculated using the Friedewald equation (total cholesterol - HDL cholesterol - (triglycerides/2.2)) and the atherogenic index of plasma (log (TG/HDL)).

In addition, blood was collected for DNA isolation. DNA was isolated using a standard salting out method (15). The MC4R rs17782313 polymorphism and rs17817449 variant within the FTO gene were determined by PCR-RFLP as previously described in detail $(16,17)$.

The principle of phospholipase activity is based on substrate conversion. The antibody-based sandwich enzyme, immunoassay, was used to determine the concentration thereof.

Standard statistical methods for comparing the differences between the monitored parameters before and after the intervention (t-test and the non-parametric Wilcoxon test, Chi-square test, ANOVA and ANCOVA) were used for statistical processing.

\section{Examined Individuals}

Within the study, the results of 349 obese children aged 9-16 years, average age $13.7 \pm 2.1$ years, average height $163 \pm 10.6$ 
Table 1. Input and output values and differences in values before and after intervention

\begin{tabular}{|c|c|c|c|c|}
\hline Parameter & Input & Output & Difference & $\mathrm{p}$ \\
\hline Weight (kg) & $81.43 \pm 19.92$ & $75.06 \pm 18.28$ & $6.37 \pm 2.26$ & $<0.001$ \\
\hline $\mathrm{BMI}\left(\mathrm{kg} / \mathrm{m}^{2}\right)$ & $30.78 \pm 4.58$ & $28.44 \pm 4.28$ & $2.33 \pm 0.78$ & $<0.001$ \\
\hline Waist circumference $(\mathrm{cm})$ & $88.7 \pm 11.3$ & $83.1 \pm 10.5$ & $5.6 \pm 3.1$ & $<0.001$ \\
\hline Abdominal circumference (cm) & $101.9 \pm 11.7$ & $96.0 \pm 11.6$ & $5.8 \pm 3.8$ & $<0.001$ \\
\hline Hip circumference $(\mathrm{cm})$ & $104.0 \pm 11.2$ & $98.6 \pm 10.8$ & $5.4 \pm 3.8$ & $<0.001$ \\
\hline Abdominal skinfold (cm) & $4.06 \pm 0.93$ & $3.3 \pm 0.6$ & $0.74 \pm 0.73$ & $<0.001$ \\
\hline Triceps skinfold (cm) & $2.5 \pm 0.9$ & $2.0 \pm 0.7$ & $0.5 \pm 0.7$ & $<0.001$ \\
\hline Subscapular skinfold (cm) & $2.7 \pm 0.9$ & $2.2 \pm 0.8$ & $0.5 \pm 0.7$ & $<0.001$ \\
\hline $\mathrm{SBP}(\mathrm{mmHg})$ & $120.2 \pm 13.8$ & $117.2 \pm 11.9$ & $3.1 \pm 12.8$ & $<0.01$ \\
\hline $\mathrm{DBP}(\mathrm{mmHg})$ & $76.8 \pm 10.3$ & $73.1 \pm 9.53$ & $3.7 \pm 12.5$ & $<0.001$ \\
\hline Pulse (beats/min) & $83.8 \pm 12.9$ & $77.0 \pm 12.9$ & $6.83 \pm 11.8$ & $<0.001$ \\
\hline Cholesterol (mmol/L) & $4.54 \pm 0.93$ & $3.66 \pm 0.86$ & $0.89 \pm 0.55$ & $<0.001$ \\
\hline LDL (mmol/L) & $2.79 \pm 0.76$ & $2.09 \pm 0.72$ & $0.69 \pm 0.49$ & $<0.001$ \\
\hline $\mathrm{HDL}(\mathrm{mmol} / \mathrm{L})$ & $1.31 \pm 0.3$ & $1.17 \pm 0.25$ & $0.14 \pm 0.18$ & $<0.001$ \\
\hline $\mathrm{TG}(\mathrm{mmol} / \mathrm{L})$ & $1.01 \pm 0.57$ & $0.82 \pm 0.32$ & $0.19 \pm 0.45$ & $<0.001$ \\
\hline apo A (mmol/L) & $1.29 \pm 0.18$ & $1.08 \pm 0.17$ & $0.21 \pm 0.12$ & $<0.001$ \\
\hline apo B (mmol/L) & $0.88 \pm 0.22$ & $0.75 \pm 0.24$ & $0.13 \pm 0.16$ & $<0.001$ \\
\hline Lp (a) (mmol/L) & $0.28 \pm 0.34$ & $0.20 \pm 0.27$ & $0.08 \pm 0.12$ & $<0.001$ \\
\hline Glycaemia (mmol/L) & $4.88 \pm 0.39$ & $4.86 \pm 0.35$ & $0.02 \pm 0.4$ & ns \\
\hline C-peptide (mmol/L) & $0.82 \pm 0.3$ & $0.76 \pm 0.3$ & $0.05 \pm 0.2$ & $<0.05$ \\
\hline Insulin (mIU/L) & $13.54 \pm 7.9$ & $11.5 \pm 6.4$ & $2.0 \pm 5.9$ & $<0.001$ \\
\hline GGT ( $\mu$ kat/L) & $0.33 \pm 0.22$ & $0.22 \pm 0.11$ & $0.11 \pm 0.16$ & $<0.001$ \\
\hline
\end{tabular}

SBP - systolic blood presure, DBP - diastolic blood presure, LDL - low density cholesterol, HDL - hight density cholesterol, TG - triglycerides, apo A - apolipoprotein A, apo B - apolipoprotein B, Lp(a) - lipoprotein(a), GGT - gamma-glutamyl transferase

$\mathrm{cm}$ were statistically processed. The initial average weight was $81.43 \pm 19.9 \mathrm{~kg}$ and BMI $30.78 \pm 4.6 \mathrm{~kg} / \mathrm{m}^{2}$. As a result of the examinations a girl was newly diagnosed with familial hypercholesterolemia and subsequently excluded from monitoring. In addition, 3 boys who were being treated for arterial hypertension were excluded as well.

\section{RESULTS}

\section{Anthropometric, Laboratory Parameters}

The heaviest participant was a 15 -year-old boy with a BMI of 50 and weight of $158 \mathrm{~kg}$, who reduced his weight to $146 \mathrm{~kg}$. During the children's reduction programme there was a statistically significant decrease in weight $(\mathrm{p}<0.001)$, BMI $(\mathrm{p}<0.001)$, reduction in skinfold thickness $(\mathrm{p}<0.001)$, and waist circumference $(p<0.001)$, as well as abdomen and hips circumference. Simultaneously, there was a statistically significant decrease in both systolic $(\mathrm{p}<0.01)$ and diastolic $(\mathrm{p}<0.001)$ blood pressure as well as a decrease in heart rate $(\mathrm{p}<0.001)$.

Laboratory tests showed a statistically significant decrease in both total and LDL, HDL cholesterol, triglycerides and monitored apolipoproteins (apo A, apo B, Lp(a)) $(\mathrm{p}<0.001)$. During monitoring, a decrease in gamma-glutamyl transferase was detected. Although the blood glucose levels remained statistically unchanged, there was a decline in the levels of C-peptide $(\mathrm{p}<0.05)$ and a significant decrease in insulinemia $(\mathrm{p}<0.001)$. Accurate input and output values as well as the differences in values before and after the intervention with appropriate $p$ values are given in Table 1 .

\section{FTO, MC4R VARIANTS}

As previously described in detail (17), in a subgroup of children with complete data, FTO and MC4R variants were genotyped. No gender differences were identified in the genotype distribution. If compared with a set of Czech adults (post-MONICA study) a higher frequency of the GG FTO genotype (24.9\% vs. $17.3 \%)$ and MC4R genotypes ( $4.7 \%$ in adults and $6.0 \%$ in obese probands) were detected in the children.

Individual polymorphisms had no effect on BMI, body weight, or WHR. However, the highest initial BMI were found in probands with a combination of the FTO GG and MC4R CC genotypes. On the contrary, both variants were predictors of the success of the intervention.

FTO GG homozygotes reduced BMI $(\mathrm{p}=0.02)$ and body weight $(p=0.04)$ more than for carriers of the T allele.

In case of the MC4R variant, $\mathrm{CC}$ homozygotes reduced BMI units (2.8 $\pm 0.9 \mathrm{BMI}$ units) more than for carriers of the $\mathrm{T}$ allele (2.3 \pm 0.7 BMI units).

Analyses of all genotype combinations show that carriers of at least one risk genotype, either FTO (GG) or MC4R (CC), reduced 
weight as well as BMI more efficiently than patients without the presence of these variants.

\section{Lp-PLA2}

In this study we also investigated the effect of regimen measures (diet and exercise intervention) on the Lp-PLA2 mass concentration in a subset of 40 children ( 25 girls and 15 boys) with an average age of 12.4 years. The Lp-PLA2 mass concentration was $402.0 \pm 93.7 \mu \mathrm{g} / \mathrm{L}$ before the intervention, $368.2 \pm 104.7$ $\mu \mathrm{g} / \mathrm{L}$ after the intervention. A statistically significant relationship was detected between the decrease in Lp-PLA2 values and TG levels (Fig. 1).

\section{DISCUSSION}

Reduction of weight, BMI, circumferences and skinfolds is the expected result of weight reduction programmes for children. Although the recommended standard anthropometric measurements were not carried out (4 to 7 anthropometric points, anthropometry was not the primary objective of this study), statistically significant results were achieved. A significant decrease in both the systolic and diastolic blood pressures as well as heart rate is statistically remarkable. It is accepted that the results can be challenged on the basis of measurement uncertainty, in particular by the children's decreased anxiety and fear of the measurements being taken (during the second measurement they were already aware of the procedures to be performed and knew the team in charge).

The decrease in insulin is very likely to be due to a decrease in insulin resistance associated with weight reduction in children, although the level of glycaemia was not affected likewise.

The decline in cholesterolemia and triglyceridemia was determined by dietary interventions in the diet of children (18). Despite intense physical activity, a statistically significant increase in HDL cholesterol could not be expected in such a short period of time. In our group there was even a statistically significant decline. This effect is probably due to a decrease in total cholesterolemia shortly after the dietary intervention. Exercise over a longer period of time would be required to increase the levels of HDL cholesterol. A decline in GGT, as an indirect indicator of hepatic steatosis, could be a reduction indicator for hepatosteatosis development.

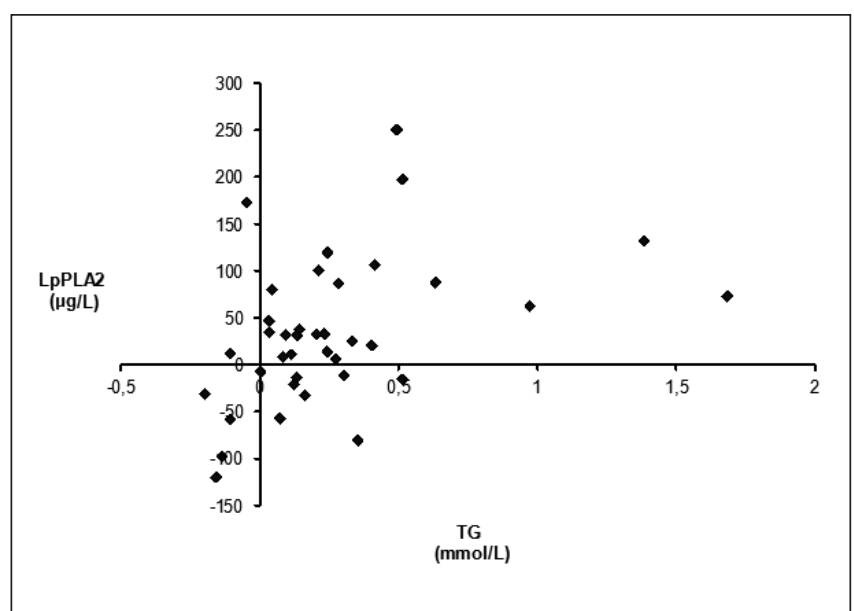

Fig. 1. Connection of Lp-PLA2 values and TG $(p<0.05)$ (14).
When monitoring decreases in body weight, significant interindividual differences were found. As previously documented (19-23), the importance of the role of FTO rs17817449 and MC4R rs17782313 variants is similar to that in adult groups (17).

Our study is the first to demonstrate the important role of the effects of FTO polymorphisms on changes to BMI in children after a short term intensive intervention programme. In our study, the children were almost completely isolated in a spa resort for a relatively short period of time. The amount of physical activity the individuals undertook was also much higher than in other studies. With 350 probands, it is one of the largest paediatric studies undertaken so far.

Previous studies $(9,12,21)$ have shown that the effect of FTO variant on BMI is similar regardless of the default BMI value. Each "risky" allele is associated with a $1.5 / 2 \mathrm{~kg}$ increase in body weight. We have proved that carriers of a risky allele respond better to lifestyle interventions and that a negative genetic predisposition can be overcome by a similar intensive lifestyle change. Non-respondents diagnosed on the basis of the FTO and MC4R genotypes will require more intensive or prolonged therapy to achieve the same effect (17).

Lp-PLA2 is a candidate for being a new supplementary atherosclerosis risk marker $(13,19,24)$. A significant decrease in Lp-PLA2 concentrations was associated with weight reduction in obese children as a result of caloric restriction and exercise. However, the concentrations remained above the values found in the healthy adult population. A possible explanation for this is the duration of the intervention and the lack of weight reduction. Further monitoring may show a larger decrease in BMI resulting in greater reductions in Lp-PLA2 concentrations. What this study has proved is that there is a clear effect from rapid weight reduction on metabolic risk factors for atherosclerosis along with markers of subclinical inflammation due to diet adjustment and physical activity. Atherosclerosis risk factors are closely associated with obesity and may already be present in childhood.

There are no data on serum concentrations of Lp-PLA2 in children with normal weight in available literature, however, the observed set of children reported significantly higher levels compared to healthy adults. We can assume that childhood obesity affects the inflammatory response of the organism more significantly than that in the adult population. This is probably due to the responsive immune system of children.

Changes in Lp-PLA2 concentrations after weight reduction were statistically significantly associated with a decrease in triglyceride levels. This relationship is probably due to the fact that higher levels of plasma triglyceride are associated with a higher proportion of small dense LDL particles, which exhibit the highest Lp-PLA2 affinity. We detected a surprisingly insignificant correlation between Lp-PLA2 and apoB. This was probably due to the small number of individuals studied.

The results show that the spa treatment for children with severe atherosclerosis risk factors is effective and should become an integral part of the care of children at risk of premature atherosclerosis. The educational effect should also not be underestimated. The children learn healthy habits which they can implement in their home environment. It is necessary to continue to identify high-risk groups of children and adults (defined by either anthropometric, laboratory or genetic indicators) in which the early manifestation of atherosclerosis can be expected. 


\section{Acknowledgement}

Supported by grant NT14152-3/2013 of the Ministry of Health of the Czech Republic

\section{Conflict of Interest}

None declared

\section{REFERENCES}

1. Češka R, Kvasilová M, Procházková R, Šmelková G, Vrablík M Hyperlipoproteinaemia and dyslipoproteinaemia I. Classification, diagnostics, cardiovascular, cardiometabolic and residual risk. Vnitr Lek. 2010;56(6):526-31. (In Czech.)

2. Karnik S, Kanekar A. Childhood obesity: a global public health crisis. Int J Prev Med. 2012 Jan;3(1):1-7.

3. Kunešová M, Vignerová J, Pařízková J, Procházka B, Braunerová R, Riedlová J, et al. Long-term changes in prevalence of overweight and obesity in Czech 7-year-old children: evaluation of different cut-off criteria of childhood obesity. Obes Rev. 2011 Jul;12(7):483-91.

4. Zlatohlávek L, Urbanová Z, Vrablík M, Prusíková M, Češka R. Monitoring atherosclerotic factors in obese children. Cesk-Slov Pediatr. 2011;66(3):153-6. (In Czech.)

5. Peng S, Zhu Y, Xu F, Ren X, Li X, Lai M. FTO gene polymorphisms and obesity risk: a meta-analysis. BMC Med. 2011 Jun 8;9:71. doi: 10.1186/1741-7015-9-71.

6. Anderson PM, Butcher KE. Childhood obesity: trends and potential causes. Future Child. 2006 Spring;16(1):19-45.

7. Češka R, Krutská S, Kašná L, Šmelková G, Zlatohlávek L, Vrablík M. Hyperlipoproteinaemia and dyslipoproteinaemia II. Therapy: non-pharmacological and pharmacological approaches. Vnitr Lek. 2010;56(7):64754. (In Czech.)

8. Rankinen T, Roth SM, Bray MS, Loos R, Pérusse L, Wolfarth B, et al. Advances in exercise, fitness, and performance genomics. Med Sci Sports Exerc. 2010 May;42(5):835-46.

9. Hubacek JA, Stanek V, Gebauerová M, Pilipcincová A, Dlouhá D, Poledne $\mathrm{R}$, et al. A FTO variant and risk of acute coronary syndrome. Clin Chim Acta. 2010 Aug 5;411(15-16):1069-72.

10. Haupt A, Thamer C, Heni M, Tschritter O, Machann J, Schick F, et al. Impact of variation near MC4R on whole-body fat distribution, liver fat, and weight loss. Obesity (Silver Spring). 2009 Oct; 17(10):1942-5.

11. Loos RJ, Lindgren CM, Li S, Wheeler E, Zhao JH, Prokopenko I, et al. Common variants near MC4R are associated with fat mass, weight and risk of obesity. Nat Genet. 2008 Jun;40(6):768-75.
12. Dlouhá D, Hubáček JA. FTO gene and his role in genetic determination of obesity. Vnitr Lek. 2012;58(3):208-15. (In Czech.)

13. Zalewski A, Nelson JJ, Hegg L, Macphee C. Lp-PLA2: a new kid on the block. Clin Chem. 2006 Sep;52(9):1645-50.

14. Motykova E, Zlatohlavek L, Prusikova M, Lanska V, Ceska R, Vasickova $\mathrm{L}$, et al. Lifestyle modification induced weight loss and changes of cardiometabolic risk factors including lowering of inflammatory response in obese children. Neuro Endocrinol Lett. 2011;32 Suppl 2:55-9.

15. Miller SA, Dykes DD, Polesky HF. A simple salting out procedure for extracting DNA from human nucleated cells. Nucleic Acid Res. 1988;16(3):1215.

16. Hubáček JA, Pikhart H, Peasey A, Kubínová R, Bobák M. FTO variant, energy intake, physical activity and basal metabolic rate in Caucasians. The HAPIEE study. Physiol Res. 2011;60(1):175-83.

17. Zlatohlavek L, Vrablik M, Motykova E, Ceska R, Vasickova L, Dlouha D, et al. FTO and MC4R gene variants determine BMI changes in children after intensive lifestyle intervention. Clin Biochem. 2013 Mar;46(45):313-6.

18. Zlatohlavek L, Vrablik M, Ceska R, Adamkova V, Urbanova Z, Prusikova $\mathrm{M}$, et al. APOA5 haplotypes determine triglyceride decrease after lifestyle induced weight loss in children. Nutr Metab Cardiovasc Dis. 2012 Sep;22(9):e22-3.

19. Dada N, Kim NW, Wolfert RL. Lp-PLA2: an emerging biomarker of coronary heart disease. Expert Rev Mol Diagn. 2002 Jan;2(1):17-22.

20. Hubacek JA, Pitha J, Adamkova V, Lanska V, Poledne R. A common variant in the FTO gene is associated with body mass index in males and postmenopausal females but not in premenopausal females. Czech postMONICA and 3PMFs studies. Clin Chem Lab Med. 2009;47(4):387-90.

21. Rendo T, Moleres A, Marti Del Moral A. Effects of the FTO gene on lifestyle intervention studies in children. Obes Facts. 2009;2(6):393-9.

22. Dlouhá D, Suchánek P, Lánská V, Hubáček JA. Body mass index change in females after short-time life style intervention is not dependent on the FTO polymorphisms. Physiol Res. 2011;60(1):199-202.

23. Balthasar N, Dalgaard LT, Lee CE, Yu J, Funahashi H, Williams T, et al. Divergence of melanocortin pathways in the control of food intake and energy expenditure. Cell. 2005 Nov 4;123(3):493-505.

24. Caslake MJ, Packard CJ. Lipoprotein-associated phospholipase A2 (platelet-activating factor acetylhydrolase) and cardiovascular disease. Curr Opin Lipidol. 2003 Aug;14(4):347-52.

Received November 14, 2014 Accepted in revised form August 13, 2015 